\title{
CONTRIBUIÇÃO PARA UM ESTUDO SOBRE O VOCÁBULO MÓRFICO
}

\section{Délcio Barros da Silva}

\section{INTRODUÇÃO}

As gramáticas normativas não aplicam uma análise precisa, completa e sistemática ao vocábulo mórfico, dificuldade essa que remonta à gramática grecolatina, de cuja técnica se nutriram. Neste trabalho, propõe-se uma verificação da conceituação dos elementos constitutivos do vocábulo, veiculada pelas principais gramáticas da língua portuguesa, examinam-se as noções de flexão e derivação e, finalmente, apresenta-se uma discussão da análise morfológica de acordo com a nomenclatura proposta pela lingüística estrutural. Alerta-se, $a b$ initio, que o presente estudo não tem a pretensão de ser exaustivo.

\section{CONCEITUAÇÕES DE GRAMÁTICA}

O emprego coloquial do termo "gramática" coincide com o que se entende por gramática-livro, tradicional ou normativa, voltada para o ensino da modalidade culta da língua. Essa gramática tem origem nos estudos teóricos das línguas clássicas (o grego e o latim), que se converteram em objeto de reflexão e, logo, de ensino, regida pelos mesmos princípios da lógica filosófica.

Naquela época, criou-se a idéia de que a língua falada era inferior e que a gramática teria como propósito impedir as incorreções da linguagem coloquial, definindo-se como "ciência que ensina a falar e escrever corretamente". Esse caráter normativo da gramática tradicional perdura até hoje, especialmente quando se considera somente a modalidade culta no ensino da língua, voltada para a escrita, como tarefa principal da escola. Trata-se, portanto, do produto do trabalho dos gramáticos com a dupla função de prescrever (explicitar as regras do que se deve e do que não se deve dizer ou escrever) e analisar as formas encontradas na língua padrão.

Já o termo "gramática", que designa o produto do trabalho do lingüista, distinguese do seu emprego coloquial referente a livro que prescreve as regras do bem falar e escrever. Em vez disso, ela procura descrever a estrutura da língua, com base na observação do que se diz ou escreve na realidade, sem a preocupação de estabelecer normas que distingam a forma "correta" da "incorreta". SILVA \& KOCH (1987:12), a seguir, caracterizam, de maneira muito clara, a oposição dessa abordagem descritiva em relação à normativa:

A primeira explicita, enumera e classifica a estrutura das frases, dos morfemas que constituem as frases, dos fonemas que constituem os morfemas e das regras de combinações dessas diferentes unidades. Trata-se de um trabalho de definição, classificação, interpretação e não de julgamento ou 
legislação. A última procura prescrever as normas, discriminando os padrões lingüísticos e elegendo um deles como de "bom uso", muitas vezes a partir de critérios de ordem social e não lingüística. Ao longo dos anos, as gramáticas normativas foram estabelecendo preceitos avaliativos, isto é, instruções que muitas vezes se resolvem em diga $x$, não diga $y$.

\section{PRINCÍPIOS BÁSICOS DO ESTRUTURALISMO}

Pode-se afirmar que a lingüística e a gramática tradicional estudam o mesmo objeto, ou seja, a língua, mas sob pontos de vista diferentes. SAUSSURE (1974) estabelece uma série de princípios que refletem as diversas formas de abordagem lingüística, através das dicotomias língua e fala, sintagma e paradigma, diacronia e sincronia, descritivo e normativo, além da dupla articulação da linguagem.

Embora esses princípios estejam estreitamente relacionados na abordagem do vocábulo mórfico, aos propósitos deste trabalho interessam, de maneira particular, a diacronia e a sincronia. A língua, em dado momento, é conseqüência de uma evolução que, por sua vez, constitui-se numa etapa evolutiva que continuará através do tempo. Ao estudo desses fenômenos lingüísticos que se modificam numa sucessão histórica chama-se diacronia, enquanto a abordagem da língua, considerando apenas uma de suas etapas evolutivas, é denominada sincronia.

Para Saussure, o estudo fundamental que deve desenvolver a lingüística é o de um determinado estágio da língua, sem levar em conta a ação do tempo sobre ela, ou seja, a realização de uma abordagem sincrônica.

\section{OS ELEMENTOS CONSTITUTIVOS DO VOCÁBULO}

Na análise do vocábulo mórfico, os conceitos de raiz, radical, vogal temática, tema e afixos constituem as primeiras dificuldades, pois as distinções, nos casos de raiz, radical e tema, nem sempre são suficientemente claras nas principais gramáticas normativas. CUNHA(1976), BECHARA(1975) e LUFT(1979), por exemplo, afirmam que tema é o radical acrescido de vogal temática; no entanto, o primeiro autor evita mencionar o conceito de raiz, mesmo quando se refere a famílias de palavras (cognatos), enquanto que, para Bechara e Luft, raiz se confunde com o radical primário, devido a este não possuir afixo. CÂMARA (1969:51), no qual se basearam os três autores citados anteriormente, reconhece, desde o latim, as dificuldades de se fazer uma distinção entre radical (incluindo-se nesse conceito o de raiz) e o tema. Para ele, "o tema vem a ser um radical ampliado por uma vogal (temática) determinada".

Mas há alguns gramáticos ilustres, entre eles COUTINHO(1971:116), que não faz, a rigor, nenhuma distinção entre raiz, radical e tema: "À parte da palavra que permanece depois da eliminação do sufixo, dá-se o nome de radical. Pode este ser constituído pela própria raiz acrescida de outro elemento de formação. Neste último caso, tem ainda o nome de tema". É importante salientar que, de acordo 
com essa nomenclatura, em vocábulos atemáticos como "fé", raiz, radical e tema coincidem.

Como se pôde verificar, os conceitos de raiz e radical são tomados como equivalentes por alguns autores, radical e tema, por outros, permitindo admitir-se que o radical e os afixos constituem os elementos básicos do vocábulo. Os afixos se subdividem em prefixos e sufixos, de acordo com a posição de ocorrência. Os prefixos vêm prepostos ao radical, por exemplo: o elemento re-, de "renovar". Os sufixos ocorrem pospostos ao radical, como o elemento -mente, no advérbio "rapidamente".

No que se refere aos afixos, há também algumas discordâncias entre as principais gramáticas normativas da língua portuguesa. Mas o problema maior se desloca para a confusão entre as abordagens sincrônicas e diacrônicas, presentes em todos os seus critérios de análise lingüística, o que caracteriza, sem dúvida, uma forte herança da gramática histórica.

CÂMARA (op.cit.) cita o exemplo do verbo "comer", cuja análise correta, pelo critério sincrônico, é com- e -er e, não, com-, prefixo, e -e, raiz, craseada pela terminação -er, segundo o modelo latino ("com-ed-ere"). Neste caso, seria um absurdo aplicar-se uma análise diacrônica para explicar que o significado de com(de "comedere") tem o mesmo valor sincrônico de com- (de "comer") em português.

\section{FLEXÃO E DERIVAÇÃO}

A flexão e a derivação constituem outro ponto de divergências e confusões nas principais gramáticas normativas do português.

"Flexão" deriva-se de "fléctere" = dobrar, flexionar. Na nomenclatura gramatical latina, o verbo "fléctere" era empregado com os sentidos de flexionar ou derivar. Hoje, no entanto, flexionar e derivar são processos distintos que precisam ficar bem claros nas gramáticas normativas. Varrão percebeu isso, criando os conceitos de "derivatio naturalis" para flexão e "derivatio voluntaria" para derivação. A flexão ou "derivatio naturalis", como dizia Varrão, é imposta pela natureza da língua. Para expressar a idéia de plural, há necessidade de flexionar as palavras: de "casa" para "casas", etc. Já na derivação ou "derivatio voluntaria", Varrão percebeu que esta é opcional, que depende da vontade do falante. Em vez de "tristíssimo", por exemplo, pode o falante empregar "muito triste" ou, mais enfaticamente, "muito, muito triste", "pra lá de triste", etc.

Outro aspecto que se pode ressaltar é a sistematicidade do processo de flexão versus a assistematicidade da derivação. No processo de flexão, não há espaço para a criatividade do falante: se o -s é a marca do plural em português, o falante não poderá expressá-lo, trocando o $-s$ por $-i$, por exemplo, de "casas" dizer "casal", etc. Na derivação, por outro lado, devido à sua assistematicidade e imprevisibilidade, a língua se recria e se enriquece através da atuação e das necessidades de comunicação de seus usuários. Se é verdade que de "negro" se terá "negrume" - o que não se garante que de "verde" se terá "verdume" - de 
"aids", tem-se "aidético", de "sineta", "sinetaço", etc.

STEFFEN(s/d) alerta que não se pode concordar totalmente com os conceitos de flexão veiculados por algumas gramáticas, onde afirmam que substantivos e adjetivos se flexionam em gênero, número e grau. De acordo com esse autor, a flexão de grau não é feita por um sufixo flexional, mas por um sufixo derivacional. Isso porque o sufixo flexional se presta a estabelecer relações gramaticais e, não, à formação de palavras. Por isso, julga-se falsa a afirmação de que os nomes se flexionam em grau, citando o caso do superlativo absoluto sintético, para comprovar esse fato.

Em português, há somente dois sufixos flexionais na flexão de substantivos e adjetivos: o de gênero e o de número. Numa análise superficial, o vocábulo "menina" apresenta um sufixo flexional de gênero $-a$; "meninas", um sufixo flexional de gênero $-a$ e outro de número $-s=$ dois sufixos flexionais. Já em "tristíssimas", expressando o superlativo absoluto sintético, têm-se dois sufixos derivacionais -iss e -im, um sufixo flexional de gênero -a e outro indicador de número $-s$.

\section{A ABORDAGEM ESTRUTURALISTA}

Na abordagem estruturalista, como o próprio nome sugere, há uma preocupação com a determinação da estrutura mórfica do vocábulo. Para tanto, é fundamental o conceito de morfema, proposto por HOCKETT(1973), da escola estruturalista americana: morfemas são os elementos mínimos individualmente significantes nas elocuções de uma língua.

Um morfema pode ser um vocábulo, embora não possa ser confundido com este. Em português, "fé" é um vocábulo e um morfema, ao mesmo tempo, pois não pode ser dividido em partes significativas. Aliás, o lingüista norte-americano Leonard Bloomfield definiu o léxico como o conjunto total de morfemas numa língua, ou seja, o inventário efetivo de todas as suas formas mínimas significativas.

O procedimento para a identificação de um morfema, segundo PICKETT (op.cit.:18), é através de "um processo de substituição e comparação de porções recorrentes". Por exemplo: em "infeliz", "independente" , "inseguro" e "indócil", iné recorrente e significa "não"; mas, numa posição adjacente, na qual as outras partes podem ser substituídas, verifica-se que, com cada substituição, dá-se mudança no significado total do enunciado. Diz-se, então, que as partes substituídas estão em contraste, constituindo-se em morfemas diferentes. Veja-se o quadro a seguir:

$\begin{array}{cl}\text { in } & \text { feliz } \\ \text { in } & \text { dependente } \\ \text { in } & \text { seguro }\end{array}$


Tomando-se o vocábulo "reis" como exemplo, constata-se que "rei" é recorrente e o-s (marca de plural) contrasta com a sua própria ausência:

$\begin{array}{ll}\text { rei } & \# \\ \text { rei } & -s\end{array}$

Um vocábulo pode ser monomorfêmico, constituído de um só morfema (ex.: "rei"), ou polimorfêmico, contendo diversos morfemas (ex.: "infelizmente"). Há dois tipos básicos de morfemas: morfema lexical (radical) e morfema gramatical (afixos). Em "reis", têm-se "rei" como morfema lexical e -s como morfema gramatical. Diversos são os processos morfológicos que ocorrem em português, como gênero, número, tempo, modo, etc., marcados por morfemas gramaticais, além dos derivacionais, marcados pelos morfemas lexicais.

Conforme os exemplos estudados, os morfemas podem ocorrer isoladamente ou ligados a outros. Chama-se morfema livre aquele que pode ocorrer sem a presença de outro elemento, como em "rei". Já em "reis", o -s (marca de número) é uma forma presa, porque só ocorre na presença de outro, neste caso, o morfema "rei".

CÂMARA (1970) introduz ainda o conceito de forma dependente, para abranger os morfemas nem livres, nem presos, como as partículas proclíticas e enclíticas, o emprego dos artigos, etc., do português. Exemplos: "o" em "o rei"; "se" em "falase".

Tem-se ainda uma subcategorização de morfemas em formas simples, compostas e complexas, entre outras. As formas simples são as que podem ocorrer livres ou presas. O $-s$ em "reis" é um exemplo de forma simples. Os radicais são puras formas simples. As formas complexas consistem de uma forma livre e de uma ou mais formas presas. Em "infelizmente", tem-se um bom exemplo de forma complexa. Já as compostas são aquelas formadas por dois morfemas livres, como em "guarda-chuva", "guarda-roupa" e tantos outros exemplos de justaposição citados nas gramáticas.

A análise morfológica estruturalista tem recebido muitas restrições dos especialistas. BASíLIO(1987:18) assim se refere ao conceito básico (semântico) de morfema:

Como o morfema é definido em relação ao significado, cria-se um problema grave de análise, já que no léxico as palavras apresentam um significado global, que não é necessariamente uma função exclusiva do significado das partes. Como conseqüência, muitas vezes não podemos isolar o significado das partes do significado global, ou seja, muitas vezes, temos elementos constitutivos de palavras que não podem ser definidos em termos de significado. 
Caberia, talvez, justificar que não se abordou este assunto do ponto de vista do gerativismo, porque os principais autores dessa corrente lingüística reconhecem as dificuldades de se realizar a segmentação das palavras, preferindo partir do vocábulo como unidade mínima (morfema) no estudo dos grandes constituintes da oração. Veja o que afirma PERINI (1976:52) no texto a seguir:

Antes de mais nada, não devemos crer que a divisão das palavras em morfemas seja sempre uma tarefa simples como dei a entender acima. Mesmo quanto à palavra que citei como exemplo, "redistribuição", podemos ter dúvidas sobre se "distribui-" é realmente um morfema ou dois, a saber, -dis (que seria o mesmo que aparece em "dispersar", "distrair", etc.) e tribui- (que estaria em "atribuir", "retribuir", "contribuir", etc.). Encontrar um significado comum a todas as ocorrências de dis seria tão difícil quanto fazer o mesmo para todas as ocorrências de -tribui-.

\section{CONSIDERAÇÕES FINAIS}

Conforme se procurou demonstrar através do presente trabalho, apesar de as principais gramáticas normativas da língua portuguesa já terem incorporado muito das contribuições dos estudos lingüísticos sobre o vocábulo mórfico, ainda há coincidência entre os enfoques sincrônico e diacrônico, gerando confusão, principalmente no que refere aos conceitos de raiz, radical e tema. Neste aspecto, embora o termo raiz conste da Nomenclatura Gramatical Brasileira, tem se constituído numa presença perturbadora entre autores das principais gramáticas do português.

Ainda em decorrência do que se disse acima, percebe-se que a partição do vocábulo, seja na técnica proposta pela gramática tradicional, seja na estrutural, não se constitui numa tarefa simples. E o problema assume proporções maiores, quando a gramática normativa se ampara em descrições inadequadas ou falsas, para prescrever regras destinadas ao ensino da língua portuguesa. Faz-se necessário, portanto, ao professor, adotando sempre uma postura crítica, buscar na descrição sincrônica da estrutura morfológica do português, em sua modalidade escrita, as bases de seu trabalho em sala de aula.

É claro que, nos limites deste artigo, caiu-se num mero relato de algumas questões de morfêmica, alinhavando-se aqui ou ali, superficialmente, a análise de alguns casos. Fica, portanto, como sugestão, um reexame deste tema para um trabalho de maior fôlego.

\section{BIBLIOGRAFIA}

BASÍLIO, Margarida. Teoria Lexical. São Paulo : Ática, 1987, p. 18. BECHARA, Evanildo. Moderna Gramática Portuguesa. São Paulo : Ed. Nacional, 1975, p. 168.

CÂMARA, Mattoso. Problemas de Lingüística Descritiva. Petrópolis : Vozes, 1969, p. 51. 
p. 61.

Estrutura da Língua Portuguesa. Petrópolis : Vozes, 1970,

CARONE, Flávia de Barros. Morfossintaxe. São Paulo : Ática, 1986.

COUTINHO, Ismael de Lima. Gramática Histórica. Rio de Janeiro : Acadêmica, 1971 , p. 116.

CUNHA, Celso. Gramática do Português Contemporâneo. Belo Horizonte : Ed. Bernardo Álvares, 1976, p. 58.

KEHDI, Valter. Morfemas do Português. São Paulo : Ática, 1990.

HOCKETT, Carles F. A Course in Modern Linguistics. In: PICKETT, Velma \& ELSON, Benjamin. Introdução à Morfologia e à Sintaxe. Petrópolis : Vozes, 1973.

LUFT, Celso Pedro. Moderna Gramática Brasileira. Porto Alegre : Globo, 1979, p. 95.

MACAMBIRA, José Rebouças. A Estrutura Morfo-sintática do Português. São Paulo : Pioneira, 1978.

PERINI, Mário. A Gramática Gerativa. Belo Horizonte : Ed. Vigília, 1976.

PICKETT, Velma \& ELSON, Benjamin. Introdução à Morfologia e à Sintaxe. Petrópolis : Vozes, 1973, p. 18.

SAUSSURE, Ferdinand. Curso de Lingüística Geral. São Paulo : Cultrix, 1974. SILVA, M. Cecília P. de Souza e KOCH, Ingedore Villaça. Lingüística Aplicada ao Português; Morfologia. São Paulo : Cortez, 1987.

STEFFEN, Elemar A. A Estrutura do Superlativo Absoluto Sintético Português. (s/d), mimeo. 